\title{
Ohmic contacts on silicon carbide: The first monolayer and its electronic effect
}

\section{AUTHOR(S):}

Wang, Zhongchang; Tsukimoto, Susumu; Saito, Mitsuhiro; Ito, Kazuhiro; Murakami, Masanori; Ikuhara, Yuichi

\section{CITATION:}

Wang, Zhongchang ...[et al]. Ohmic contacts on silicon carbide: The first monolayer and its electronic effect. PHYSICAL REVIEW B 2009, 80(24): 245303.

\section{ISSUE DATE:}

2009-12

URL:

http://hdl.handle.net/2433/109865

RIGHT:

(c) 2009 The American Physical Society 


\title{
$\mathcal{S}^{\circ}$ \\ Ohmic contacts on silicon carbide: The first monolayer and its electronic effect
}

\author{
Zhongchang Wang, ${ }^{1, *}$ Susumu Tsukimoto, ${ }^{1}$ Mitsuhiro Saito, ${ }^{1}$ Kazuhiro Ito, ${ }^{2}$ Masanori Murakami, ${ }^{3}$ and Yuichi Ikuhara ${ }^{1,4}$ \\ ${ }^{1}$ World Premier International Research Center, Advanced Institute for Materials Research, Tohoku University, 2-1-1 Katahira, \\ Aoba-ku, Sendai 980-8577, Japan \\ ${ }^{2}$ Department of Materials Science and Engineering, Kyoto University, Kyoto 606-8501, Japan \\ ${ }^{3}$ The Ritsumeikan Trust, Nakagyo-ku, Kyoto 604-8520, Japan \\ ${ }^{4}$ Institute of Engineering Innovation, The University of Tokyo, 2-11-16 Yayoi, Bunkyo-ku, Tokyo 113-8656, Japan
}

(Received 31 August 2009; revised manuscript received 3 November 2009; published 1 December 2009)

\begin{abstract}
We demonstrate that origin of the long-standing contact issue in silicon carbide devices can be understood and technologically manipulated at the atomic level. Using advanced transmission electron microscopy, we attribute qualitatively the formation of ohmic contacts to silicon carbide to an epitaxial, coherent, and atomically ordered interface. Quantitatively, first-principles calculations predict that this interface can trap an atomic layer of carbon and hence enable lowered Schottky barrier and enhanced quantum electron transport. The combined experimental and theoretical studies performed provide insight into the complex electronic and electric effects of the buried contact interface, which are fundamental for improving the contact in future electronics based on wide-band-gap semiconductors such as silicon carbide and diamond.
\end{abstract}

DOI: 10.1103/PhysRevB.80.245303 PACS number(s): 68.37. $-\mathrm{d}, 68.35 .-\mathrm{p}, 68.60 .-\mathrm{p}, 68.55 .-\mathrm{a}$

\section{INTRODUCTION}

One of the most active fields in semiconductor research is the development of electronic devices capable of function at high power and frequency levels, high temperatures, and caustic circumstances. ${ }^{1,2}$ This surge of activity is strongly driven by the urgent desire for replacing the current $\mathrm{Si}$ and GaAs-based electronics because they are unable to operate properly under harsh environmental conditions. ${ }^{3,4}$ As a promising substitute, the wide-band-gap semiconductor, silicon carbide $(\mathrm{SiC}),{ }^{5}$ has captured considerable attention recently due to its excellent intrinsic properties, ${ }^{6,7}$ which involve large breakdown electric field, high electron saturation drift velocity, strong hardness, and good thermal conductivity. ${ }^{8,9}$ On the other hand, current significant improvements in its epitaxial and bulk crystal growth have paved the way for fabricating its electronic devices, which stimulates further interest in developing device processing techniques so as to take full advantage of its superior inherent properties.

One of the most critical issues currently limiting the device processing is the manufacturing of reliable and lowresistance ohmic contacts especially contacts to $p$-type 4H-SiC. ${ }^{10,11}$ The ohmic contacts are primarily important in $\mathrm{SiC}$ devices because a Schottky barrier of high energy is inclined to form at an interface between metal and wideband-gap semiconductor, which consequently results in lowcurrent driving, slow switching speed, and increased power dissipation. Much of effort expended to date to realize the ohmic contact has mainly focused on two techniques. One is the high-dose ion-implantation approach, ${ }^{12,13}$ which can increase the carrier density of $\mathrm{SiC}$ noticeably and reduce its depletion width significantly so that increasing tunneling current is able to flow across barrier region. The key problem of this method is the easy formation of lattice defects or amorphization during the ion implantation. These defects are unfortunately very stable and need to be recovered via annealing at an extremely high temperature $(\sim 2000 \mathrm{~K})$, thereby complicating the mass production of $\mathrm{SiC}$ devices.
The other alternative is to generate an intermediate semiconductor layer with narrower band gap or higher carrier density at the contacts/SiC interface via depositing and annealing technique. ${ }^{14,15}$ To form such layers, many materials have been examined in a trial-and-error designing fashion, including metals, ${ }^{16}$ silicides, ${ }^{17}$ carbides, ${ }^{18}$ nitrides, ${ }^{19}$ and graphite. $^{20}$ Of all these materials, the metallic alloys have been investigated extensively, ${ }^{21,22}$ largely because their fabrication process is simple, standard, and requires no exotic materials. In particular, most of research activities have been focused on TiAl-based alloys, the only currently available materials that yield significantly low contact resistance (ohmic contact) to $p$ SiC. ${ }^{23,24}$ Moreover, they demonstrate high thermal stability. ${ }^{1}$ Although a lot of intriguing results have been obtained regarding the TiAl-based contact systems, ${ }^{25,26}$ the mechanism whereby the Schottky becomes ohmic after annealing has not been well clarified yet. In other words, the key factor to understanding the formation origin of ohmic contact remains controversial. Mohney et al. ${ }^{27}$ proposed that a high density of surface pits and spikes underneath the contacts contributes to the formation of ohmic behavior based on their observations using scanning electron microscopy and atomic force microscopy. Nakatsuka et al. ${ }^{28}$ however, concluded that the $\mathrm{Al}$ concentration in the TiAl alloy is important for the contact formation. Using the liquid etch and ion-milling techniques, John and Capano ${ }^{29}$ ruled out these possibilities and claimed that what matters in realizing the ohmic character is the generation of carbides, $\mathrm{Ti}_{3} \mathrm{SiC}_{2}$ and $\mathrm{Al}_{4} \mathrm{C}_{3}$, between the metals and semiconductor. This, however, differs, to some extent, from the x-ray diffraction (XRD) findings of Chang et al. ${ }^{30}$ showing that the compounds formed at the metal/SiC interface are silicides, $\mathrm{TiSi}_{2}$, $\mathrm{TiSi}$, and $\mathrm{Ti}_{3} \mathrm{SiC}_{2}$. In addition, Ohyanagi et al. ${ }^{31}$ argued that carbon exists at the contacts/SiC interface and might play a crucial role in lowering Schottky barrier. These are just a few representative examples illustrating the obvious discrepancies in clarifying the formation mechanism of ohmic contact. Taking the amount of speculations on the mechanism and the 
increasing needs for better device design and performance control, understanding the underlying formation origin is timely and relevant.

To develop an understanding of the origin in such a complex system, it is important to focus first on microstructure characterization. Transmission electron microscopy (TEM) studies by Tsukimoto et al. ${ }^{32,33}$ have provided useful information in this aspect. They have found that the majority of compounds generated on the surface of $4 \mathrm{H}-\mathrm{SiC}$ substrate after annealing consist of $\mathrm{Ti}_{3} \mathrm{SiC}_{2}$ and hence proposed that the $\mathrm{SiC} / \mathrm{Ti}_{3} \mathrm{SiC}_{2}$ interface is responsible for the lowering of Schottky barrier in the TiAl-based contact system. However, the role of this interface in realizing the ohmic nature is still unclear. It is not even clear how the two materials atomically bond together from their experiments, which is very important because it may strongly affect physical properties of the system. Theoretically, we have calculated the atomic structures, adhesive energies, and bonding nature of the $\mathrm{SiC} / \mathrm{Ti}_{3} \mathrm{SiC}_{2}$ interface. ${ }^{34}$ However, this calculation does not actually reveal the formation mechanism of ohmic contact because it only addresses interface structure. Furthermore, lacking essential experimental information about the interfacial atomic-scale structure, such calculations have been incomplete.

Recent advances in the high-angle annular-dark-field (HAADF) microscopy, ${ }^{35,36}$ the highest resolution, have enabled atomic-scale imaging of a buried interface. ${ }^{37,38}$ However, direct interpretation of the observed HAADF images is not always straightforward because there might be abrupt structural discontinuity, mixing of several species of elements on individual atomic columns, or missing contrasts of light elements. One possible way out to complement the microscopic data is through atomistic calculation, especially the first-principles calculation. ${ }^{39,40}$ As well known, the atomistic first-principles simulations have long been confirmed to be able to suggest plausible structures, elucidate the reason behind the observed images, and even provide a quantitative insight into how interface governs properties of materials. Consequently, a combination of the state-of-the-art microcopy and accurate atomistic modeling is an important advance for determining interface atomic-scale structure and relating it to device properties, revealing, in this way, physics origin of the contact issues in $\mathrm{SiC}$ electronics. ${ }^{41,42}$

In addition to determining atomic structure of the $4 \mathrm{H}-\mathrm{SiC} / \mathrm{Ti}_{3} \mathrm{SiC}_{2}$ interface, the goal of this work is to clarify the formation mechanism of the TiAl-based ohmic contacts so as to provide suggestions for further improvement of the contacts. $4 \mathrm{H}-\mathrm{SiC}$ will hereafter be referred to as SiC. First of all, we fabricated the TiAl-based contacts and measured their electric properties in order to confirm the formation of ohmic contact. Next, the metals/SiC interface was analyzed using the XRD to identify reaction products and TEM, highresolution TEM (HRTEM), and scanning TEM (STEM) to observe microstructures. Based on these observations, we finally performed systematic first-principles calculations aimed to assist understanding of the ohmic contact formation at a quantum-mechanical level. Interestingly, we find that the $\mathrm{SiC}$ is totally covered by a well-defined layer-by-layer compound ${ }^{43}$ and that a carbon monolayer emerges at the interface. The presence of the atomic layer of $\mathrm{C}$ is found to enable stronger adhesion, lowered Schottky barrier, and enhanced electron transport. This $\mathrm{C}$ layer, together with the abruptness and coherency of the contact interface, is critical for understanding the origin of ohmic nature.

The rest of this paper is organized in the following way. Section II describes in detail experimental procedure and computational methodology. In Sec. III, we show experimental results on electric measurement and microstructure analysis. The calculation results of atomic structures, electronic states, bonding nature, and quantum electron transport for the experimentally observed interfaces are presented in Sec. IV, where the factors affecting the ohmic contact formation are highlighted. Finally, the formation mechanism is discussed and the results are summarized in Sec. V.

\section{EXPERIMENTAL AND CALCULATIONAL DETAILS}

The $p$-type $4 \mathrm{H}$-SiC layers doped with $\mathrm{Al}(5 \mu \mathrm{m}$ thick, $N_{\mathrm{A}}=4.5 \times 10^{18} \mathrm{~cm}^{-3}$ ), which were grown on pristine $4 \mathrm{H}-\mathrm{SiC}$ wafers by chemical-vapor deposition (Cree, Inc.), were used as substrates. The $4 \mathrm{H}-\mathrm{SiC}$ substrates have $8^{\circ}$-off $\mathrm{Si}$ terminated (0001) surfaces inclined toward [2110] direction because the $4 \mathrm{H}$ is the only $\mathrm{SiC}$ polymorph ${ }^{44,45}$ that allows lateral growth of (0001)-oriented layers. After chemically cleaning the substrate surface, a 10-nm-thick sacrificial oxide $\left(\mathrm{SiO}_{x}\right)$ layer was grown on the $\mathrm{SiC}$ substrate by dry oxidation at $1423 \mathrm{~K}$ for $60 \mathrm{~min}$. For the purpose of subsequent currentvoltage $(I-V)$ measurements, a circular electrode pattern was prepared in advance on the substrates by removing the $\mathrm{SiO}_{x}$ layer using the photolithographic technique. The substrates were first cleaned by dipping in 5\% diluted hydrofluoric acid solution and rinsing in deionized water. Then, high-purity Ti and $\mathrm{Al}$ layers were deposited sequentially onto the $\mathrm{SiC}$ substrates in a high-vacuum chamber with base pressure of lower than $5 \times 10^{-6} \mathrm{~Pa}$. The $\mathrm{Ti}$ and $\mathrm{Al}$ were evaporated by electron beam and resistance heater, respectively. The deposited $\mathrm{Ti}$ and $\mathrm{Al}$ layers were as thick as 100 and $380 \mathrm{~nm}$, respectively, as measured by a quartz oscillator during deposition. The thicknesses were selected deliberately in order to produce an average composition of $\mathrm{Ti}(20$ at. $\%)$ and $\mathrm{Al}$ (80 at. \%) because rich $\mathrm{Al}$ with more than 75 at. \% in concentration was found empirically to be beneficial for yielding low-contact resistance. ${ }^{46,47}$ After lifting off the photoresist, the binary TiAl contact layers were finally annealed at 1273 $\mathrm{K}$ for $2 \mathrm{~min}$ in an ultrahigh-vacuum chamber with pressure of less than $1 \times 10^{-7} \mathrm{~Pa}$.

Cross-section thin-foil specimens for TEM observation were prepared by first cutting several slices from the deposited contacts along the $[11 \overline{2} 0]$ plane. These slices were then mechanically grinded to a thickness of $0.1 \mathrm{~mm}$ and further dimpled down to $20 \mu \mathrm{m}$. Finally, to make an electron transparency, the dimpled slices were thinned by an argon-ion sputter beam using the PIPS 691 (Gatan Co., Ltd.) with gun voltages of 2-4 kV and beam angles of $6^{\circ}$, which had been confirmed to prevent samples from radiation damage.

The electric properties of the TiAl contacts were measured by a two-point probe method using the circular patterns with an interspacing of $8 \mu \mathrm{m}$. Microstructure analyses were performed using the XRD and TEM. For the XRD, a 
Rigaku RINT-2500 diffractometry with $\mathrm{Cu} K \alpha$ radiation operated at $30 \mathrm{kV}$ and $100 \mathrm{~mA}$ was used. The interfacial microstructures and orientation relationships were characterized by the TEM, HRTEM, and selected-area diffraction pattern (SADP), using a JEOL JEM-4000EX electron microscope operated at an accelerating voltage of $400 \mathrm{kV}$. The point-topoint resolution of this microscope was approximately 0.17 $\mathrm{nm}$. The interface atomic-scale structures were observed using the HAADF-STEM (JEM-2100F, JEOL Ltd.). The STEM used in this study was equipped with an aberration corrector (CEOS Gmbh, Heidelberg, Germany), which offers an unprecedented opportunity to probe details of interface atomic structure with a sub-angstrom electron probe. A HAADF detector with an inner semiangle of more than 60 mrad was used. Under this collection condition, the contrast of an atomic column in the incoherent HAADF image is approximately proportional to the square of atomic number (Z). ${ }^{48}$

The calculations of total energies and electronic structures were performed using the Vienna $a b$ initio simulation package (VASP) within the framework of density-functional theory (DFT). ${ }^{49,50}$ The projector augmented wave method ${ }^{51}$ was used for electron-ion interactions and the generalized gradient approximation (GGA) of Perdew et al. ${ }^{52}$ (PW91) was employed to describe the exchange-correlation functional. The single-particle Kohn-Sham wave function was expanded using the plane waves with a cutoff energy of $400 \mathrm{eV}$ and sampling of irreducible Brillion zone was carried out with a regular Monkhorst-Pack grid of $8 \times 8 \times 1 k$ points. ${ }^{53}$ For interface calculations, a vacuum region of $10 \AA$ was embedded into the supercell to avoid the unwanted interaction between the slab and its period images. ${ }^{54}$ We conducted a series of convergence tests for the interface systems and confirmed that the above parameters were sufficient to ensure totalenergy convergence to less than $1 \mathrm{meV} /$ atom. All atoms in the calculated slabs were fully relaxed using the conjugate gradient algorithm ${ }^{55}$ until the magnitude of HellmannFeynman force ${ }^{56}$ on each atom converged to less than $0.05 \mathrm{eV} / \AA$.

As for transport calculations, we applied the state-of-theart quantum transport technique, that is, the fully selfconsistent nonequilibrium Green's-function method combined with the DFT, which was implemented in Atomistix ToolKit (ATK) code. ${ }^{57,58}$ The reliability of this method was tested $^{59,60}$ and applicability of this code was examined on many systems. ${ }^{61,62}$ The core electrons were modeled with the Troullier-Matrins nonlocal pseudopotential ${ }^{63}$ while the valence electrons were expanded in a numerical atomic-orbital basis set of single zeta plus polarization. The total energy was well converged to within 1-2 meV/atom upon using 4 $\times 4 k$ points to sample the irreducible Brillouin zone and a cutoff of $100 \mathrm{Ry}$ for the grid integration to present charge density. A $10 \times 10 k$-point mesh was then used to obtain sufficiently converged transmission spectra.

\section{EXPERIMENTAL RESULTS}

\section{A. Formation of ohmic contacts}

To verify the formation of ohmic contact, we measured the electric properties ( $I-V$ characteristics) for the TiAl con-

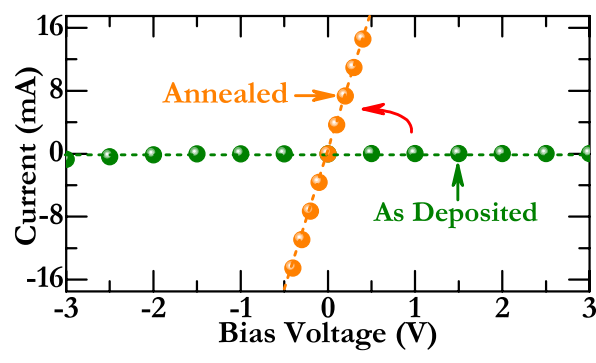

FIG. 1. (Color online) Current-voltage properties of the TiAl contact systems before and after thermal annealing at $1273 \mathrm{~K}$ for 2 $\min$.

tact systems before and after annealing, as shown in Fig. 1. For the system before annealing, its current almost maintains zero despite that the applied bias ranges from -3.0 to $3.0 \mathrm{~V}$, which clearly reflects Schottky character of this system. ${ }^{64,65}$ This can be understood by considering that the potential induced by applied bias drops largely at an contact interface between metals and semiconductors, thus hindering the current flow. The annealed system, however, exhibits a typical ohmic nature, as its $I$ - $V$ curve is nearly linear and the current increases sharply with the rise of applied bias. ${ }^{66,67}$ This drastic change in electric properties agrees well with previous experimental reports ${ }^{68-70}$ and suggests that there might be substantial changes in microstructure during the annealing.

\section{B. Identification of reaction products}

To determine chemical composition of the TiAl contact systems, we performed XRD analyses, as shown in Fig. 2, where textural orientations of the detected matters are shown as well for easy reference. As expected from the preparation process, one can see in Fig. 2(a) peaks of deposited metals, $\mathrm{Ti}$ and $\mathrm{Al}$, and the (0001)-oriented $\mathrm{SiC}$ in the system before annealing. It is worthy of mentioning that the detected Ti has a much weaker intensity of diffraction peak than the $\mathrm{Al}$, which can be attributed to its lower concentration and smaller grains. On the other hand, the XRD spectrum alters significantly after annealing [Fig. 2(b)], as the original Ti and Al peaks disappear and new peaks emerge, which suggests that chemical reactions occur at interface.

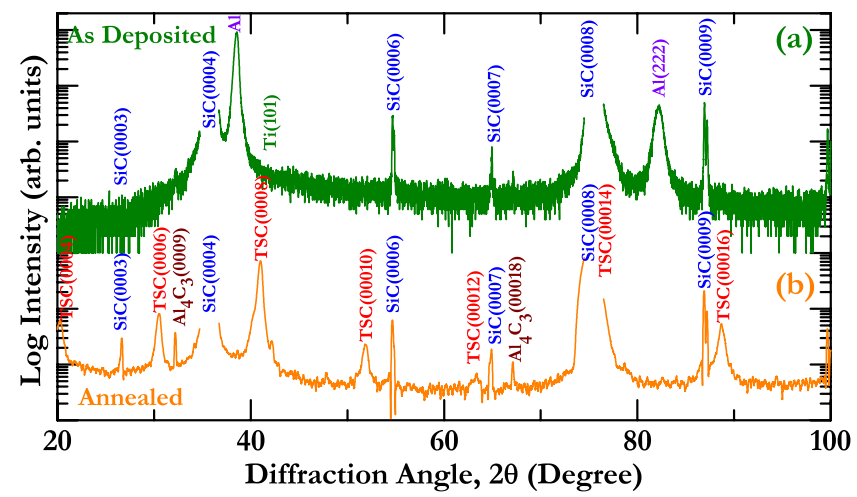

FIG. 2. (Color online) XRD spectra of (a) as-deposited and (b) annealed TiAl contact systems. Note that the TSC represents $\mathrm{Ti}_{3} \mathrm{SiC}_{2}$. 

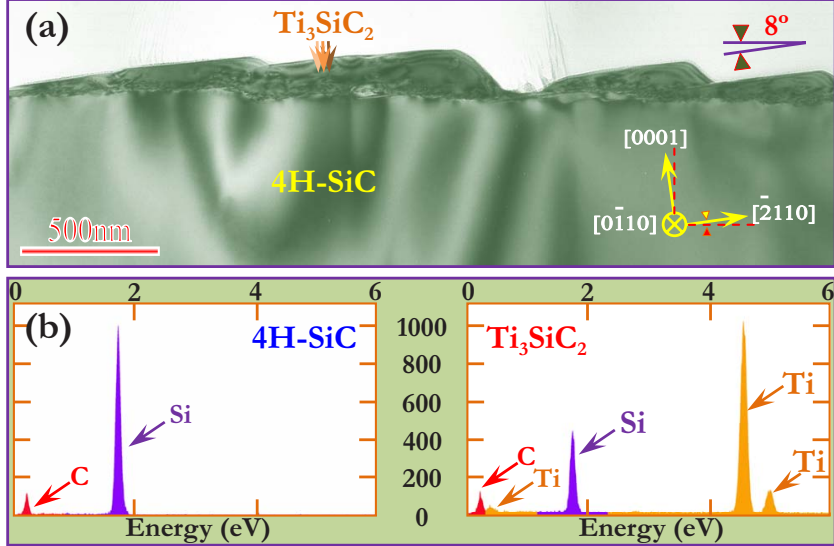

FIG. 3. (Color online) (a) Cross-sectional bright-field TEM image of the annealed $\mathrm{TiAl}$ contact system showing exclusive reaction product of $\mathrm{Ti}_{3} \mathrm{SiC}_{2}$ and (b) EDS data obtained at the $\mathrm{SiC}$ and $\mathrm{Ti}_{3} \mathrm{SiC}_{2}$ region near to interface. The vertical axis in (b) denotes the counts (i.e., intensity).

From Fig. 2(b), the reaction products are found to be dominated by ternary $\mathrm{Ti}_{3} \mathrm{SiC}_{2}$ with strongly (0001)-oriented textures, as only the $(000 l)$ diffraction peaks are observed. In addition to the $\mathrm{Ti}_{3} \mathrm{SiC}_{2}$, binary $\mathrm{Al}_{4} \mathrm{C}_{3}$ is also present in the annealed specimen. However, its amount is very small because the intensities of its diffraction peaks are comparatively much weaker. The formation of these compounds at elevated temperature is also supported by the Ti-Al-SiC equilibrium phase diagram, ${ }^{71}$ which predicts that four phases, $\mathrm{SiC}, \mathrm{Al}_{4} \mathrm{C}_{3}, \mathrm{Ti}_{3} \mathrm{SiC}_{2}$, and liquid, can coexist in an equilibrium state when the aforementioned composition of TiAl alloy is adopted. Furthermore, the XRD results agree well with the experimental reports of Jennings et al. $^{72}$ and Johnson and Capano, ${ }^{29}$ but deviate somewhat from those of Nakatsuka et al. ${ }^{28}$ which show that binary $\mathrm{Al}_{3} \mathrm{Ti}$ is present as well. This slight difference is mainly because the intensity of $\mathrm{Al}_{3} \mathrm{Ti}$ peak is so low that might be overlapped by the strong peaks of $\mathrm{SiC}$ and $\mathrm{Ti}_{3} \mathrm{SiC}_{2}$. Finally, we note that the $\mathrm{SiC}$ retains the (0001)-oriented texture after annealing, thereby facilitating the development of heteroepitaxy between the reaction products and substrates.

\section{Interfacial orientation relationships and microstructures}

Although the XRD can reveal detailed information on chemical composition of reaction products, it provides limited insight into matters concerning how the products distribute and contact the substrate. To observe the microstructure directly, we present in Fig. 3(a) a cross-sectional bright-field TEM image of a representative region in the annealed TiAl contact system. The incident electron beam is along [0 $\overline{1} 10]$ direction of the $\mathrm{SiC}$, which is parallel to the tilting axis of the $8^{\circ}$-off $\mathrm{SiC}(0001)$ surface. As seen in this figure, the $\mathrm{SiC}$ surface is covered entirely by the plate-shaped $\mathrm{Ti}_{3} \mathrm{SiC}_{2}$ with thickness ranging approximately from 30 to $300 \mathrm{~nm}$. This universal cover means that no any other compounds contact directly the $\mathrm{SiC}$ surface, thereby ensuring an exclusive contact of $\mathrm{Ti}_{3} \mathrm{SiC}_{2}$ to $\mathrm{SiC}$. Consequently, the $\mathrm{SiC} / \mathrm{Ti}_{3} \mathrm{SiC}_{2}$ inter-

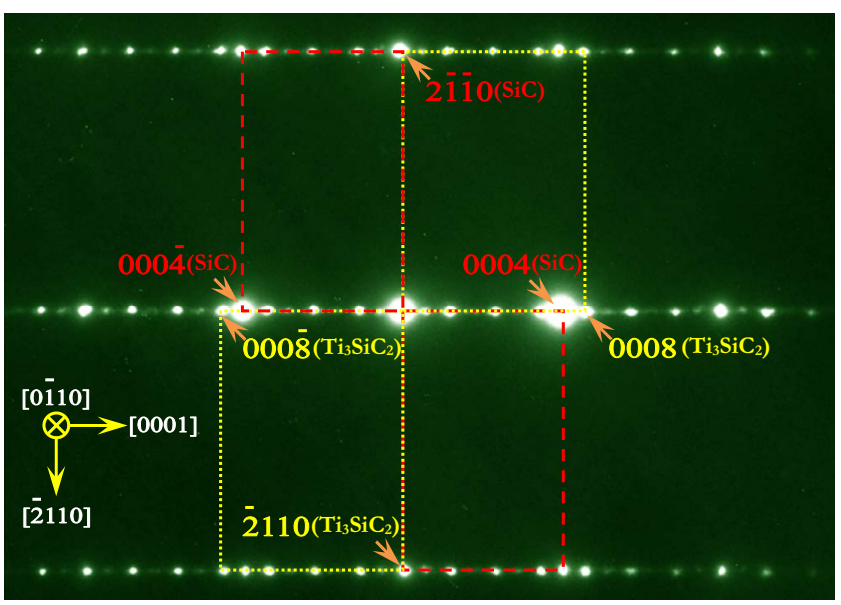

FIG. 4. (Color online) Selected-area diffraction pattern obtained at the annealed contacts/SiC interface. The arrays of diffraction spots from the $\mathrm{SiC}$ and contacts are marked by dashed and dotted lines, respectively.

face might play an essential role in the formation of ohmic contact. In addition, this interface is observed to have a sawtoothlike facet structure and the $\mathrm{Ti}_{3} \mathrm{SiC}_{2}$ surface inclines by nearly $8^{\circ}$ toward the substrate surface, suggesting that the $\mathrm{SiC}$ surface affects significantly the morphology of formed $\mathrm{Ti}_{3} \mathrm{SiC}_{2}$.

To analyze the element species around interface, we further show in Fig. 3(b) the energy-dispersive $\mathrm{x}$-ray spectroscopy (EDS) spectra for the interfacial $\mathrm{SiC}$ and $\mathrm{Ti}_{3} \mathrm{SiC}_{2}$ regions. The substrate is mainly composed of $\mathrm{C}$ and $\mathrm{Si}$ and the reaction products $\mathrm{C}, \mathrm{Si}$, and $\mathrm{Ti}$, in accordance with chemical compositions of the substrate and the main reaction products, respectively. Unexpectedly, no $\mathrm{Al}$ peak is observed in either the interfacial $\mathrm{SiC}$ or $\mathrm{Ti}_{3} \mathrm{SiC}_{2}$ area, which contravenes our previous XRD analyses showing that the $\mathrm{Al}_{4} \mathrm{C}_{3}$ compound is present in the annealed specimen. This discrepancy is mainly because the amount of $\mathrm{Al}_{4} \mathrm{C}_{3}$ is so small [Fig. 2(b)] that is hard to be detected by the EDS, or because the Al might not distribute near the interface at all but around the $\mathrm{Ti}_{3} \mathrm{SiC}_{2}$ surface instead. Whatever the reason is, the $\mathrm{Al}$ should not be the key to understanding the formation origin of ohmic contact. That is, a large amount of $\mathrm{Al}$ diffuses into the $\mathrm{SiC}$ and introduces a heavily $p$-doped $\mathrm{SiC}$, which result in narrower depletion area and thus more tunneling. As a matter of fact, Gao et al..$^{73}$ have confirmed, by analyzing interfacial chemical composition and local states, that no additional Al segregates to the interface, suggestive of a clean contact of $\mathrm{Ti}_{3} \mathrm{SiC}_{2}$ to $\mathrm{SiC}$. To further corroborate this point, the characterization using the HRTEM and STEM is needed, and this will be provided later.

Figure 4 shows a SADP at the contacts/SiC interface taken along the same electron-beam direction as in Fig. 3(a). A careful indexing of this pattern confirms again the plateshaped layers as being ternary $\mathrm{Ti}_{3} \mathrm{SiC}_{2}$. From this figure, the formed $\mathrm{Ti}_{3} \mathrm{SiC}_{2}$ layers are observed to have epitaxial orientation relationships $(0001)_{\mathrm{Ti}_{3} \mathrm{SiC}_{2}} \|(0001)_{\mathrm{SiC}}$ and $[0 \overline{1} 10]_{\mathrm{Ti}_{3} \mathrm{SiC}_{2}} \|[0 \overline{1} 10]_{\mathrm{SiC}}$ with the $\mathrm{SiC}$ substrate, which agrees well with the XRD analyses demonstrating that both materials exhibit strongly (0001)-oriented textures. These orienta- 


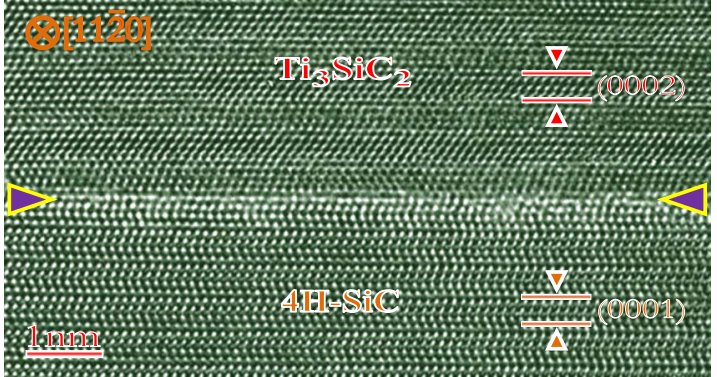

FIG. 5. (Color online) A representative cross-sectional HRTEM image of the interface between the generated $\mathrm{Ti}_{3} \mathrm{SiC}_{2}$ and the $\mathrm{SiC}$ substrate observed from the $[11 \overline{2} 0]$ direction.

tion relationships are believed to be beneficial for forming a coherent and well-matched interface between the $\mathrm{SiC}$ and $\mathrm{Ti}_{3} \mathrm{SiC}_{2},{ }^{34}$ since they both belong to the hexagonal space group with lattice constants of $a=3.081 \AA$ and $c$ $=10.085 \AA$ for the $\mathrm{SiC}$ (Refs. 74 and 75) and $a=3.068 \AA$ and $c=17.669 \AA$ for the $\mathrm{Ti}_{3} \mathrm{SiC}_{2} \cdot{ }^{76,77}$

In support of this idea, we present in Fig. 5 a crosssectional HRTEM image of the $\mathrm{SiC} / \mathrm{Ti}_{3} \mathrm{SiC}_{2}$ interface observed from the $[11 \overline{2} 0]$ direction. From this figure, one can clearly see well-arranged $(000 l)$-oriented lattice fringes along the direction parallel to the interface in both the $\mathrm{Ti}_{3} \mathrm{SiC}_{2}$ layer and $\mathrm{SiC}$ substrate (marked in Fig. 5). The points at which the phase contrast is no longer periodic in either the $\mathrm{Ti}_{3} \mathrm{SiC}_{2}$ or $\mathrm{SiC}$ define the interfacial region, as indicated by arrows. Evidently, the interface is atomically abrupt and coherent without any secondary phase layers, amorphous layers, contaminants, or transition regions, which confirms a clean and direct contact of the $\mathrm{Ti}_{3} \mathrm{SiC}_{2}$ with $\mathrm{SiC}$ on atomic scale. In addition, no misfit dislocations are visible at interface in the present HRTEM micrograph and further examination of other interfacial regions (not shown here) demonstrates that the density of misfit dislocations is extremely low in this contact system. This can be explained from the small lattice mismatch between the two materials (less than $0.5 \%$ ). Unfortunately, it remains unclear from this figure how the two materials atomically bond together at interface, which is very important because bonding nature is well known to be able to affect physical properties of interfacial systems significantly.

\section{Interfacial atomic-scale structures}

Figure 6 shows a typical HAADF image of the $\mathrm{SiC} / \mathrm{Ti}_{3} \mathrm{SiC}_{2}$ interface. A simple looking at this figure confirms a clean and atomically sharp contact between the two materials, which means that we have successfully produced epitaxially grown $\mathrm{Ti}_{3} \mathrm{SiC}_{2}$ on $\mathrm{SiC}$. Brighter spots in the image represent atomic columns of $\mathrm{Ti}$, while the comparatively darker ones are $\mathrm{Si}$, since the intensity of an atomic column in the STEM, to good approximation, is directly proportional to the square of atomic number $(Z){ }^{48,78}$ Not surprisingly, due to small atomic number of $\mathrm{C}$, its columns are not scattered strongly enough to be visualized, thereby making the image incomplete. Further complementing of this image so as to

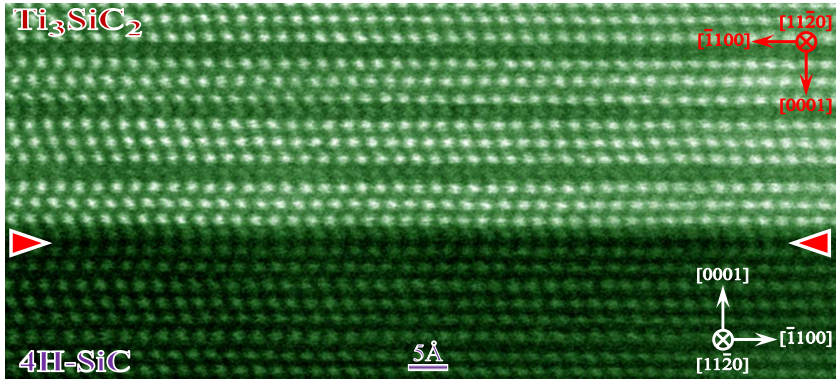

FIG. 6. (Color online) A typical HAADF-STEM image of the $\mathrm{SiC} / \mathrm{Ti}_{3} \mathrm{SiC}_{2}$ interface in the annealed TiAl contact system observed from the $[11 \overline{2} 0]$ direction. The position of interface is indicated by two arrows.

relate the atomic structure to property requires the highprecision first-principles calculations, and this will be addressed in the following section.

To see the interface atomic structure clearer, we magnify the cross-sectional HAADF image of the $\mathrm{SiC} / \mathrm{Ti}_{3} \mathrm{SiC}_{2}$ interface in Fig. 7(a) and further filter it to reduce noise, as shown in Fig. 7(b). The interface location is indicated by a horizontal line, which is determined based on the arrangement of atomic columns in bulk $\mathrm{SiC}$ and $\mathrm{Ti}_{3} \mathrm{SiC}_{2}$. The Si-terminated $\mathrm{Ti}_{3} \mathrm{SiC}_{2}$ is observed intuitively to make a direct contact with the $\mathrm{Si}$-terminated $\mathrm{SiC}$ substrate with the interfacial $\mathrm{Si}$ atoms of $\mathrm{Ti}_{3} \mathrm{SiC}_{2}$ sitting above hollow sites of the interfacial $\mathrm{Si}$ plane of SiC. However, as we will see in the upcoming simulations, this interpretation is premature in that it neglects a possibility, namely, the unseen $\mathrm{C}$ might be trapped at interface. Another interesting feature in this figure is that no $\mathrm{Al}$ columns are detected surrounding interface, which eliminates the possibility of additional $p$ doping via $\mathrm{Al}$ diffusion into the top few SiC layers. Since there are also no pits, spikes, or dislocations which might act as pathways for current transport, we conclude that the clean and coherent $\mathrm{SiC} / \mathrm{Ti}_{3} \mathrm{SiC}_{2}$ interface should be critical for the ohmic contact formation.
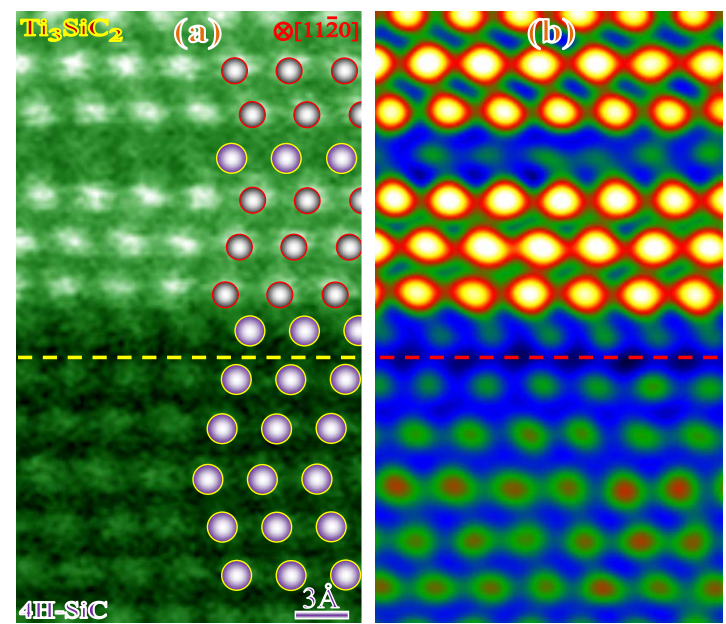

FIG. 7. (Color online) (a) Magnified HAADF image of the $\mathrm{SiC} / \mathrm{Ti}_{3} \mathrm{SiC}_{2}$ interface. An overlay is shown as well for easy reference. The bigger balls denote $\mathrm{Si}$ and the smaller ones Ti. (b) The same image as in (a) but has been low-pass filtered to reduce the noise. 


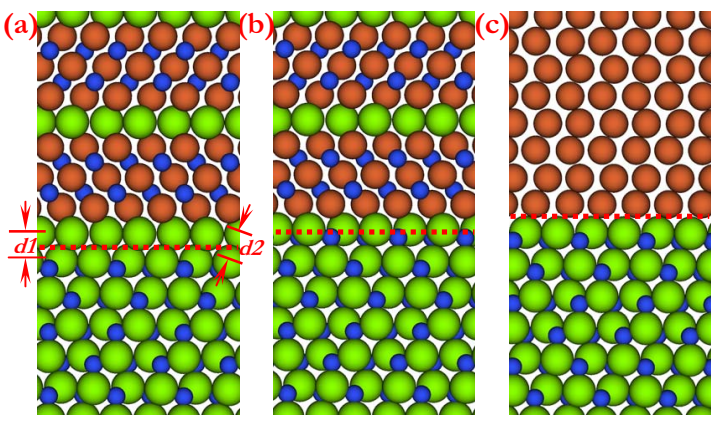

FIG. 8. (Color online) Relaxed $\mathrm{SiC}(0001) / \mathrm{Ti}_{3} \mathrm{SiC}_{2}(0001)$ interface models (a) without interfacial $\mathrm{C}$ atoms ( $\mathrm{SiSi}$ ) and (b) with interfacial $\mathrm{C}$ atoms $(\mathrm{SiCSi})$. (c) Optimized $\mathrm{SiC}(0001) / \mathrm{Ti}(0001)$ interface model. The distance between interfacial Si-Si layers [Si-Ti layers for (c)] is represented by $d 1$ and that between interfacial $\mathrm{Si}-\mathrm{Si}$ atoms $[\mathrm{Si}-\mathrm{Ti}$ atoms for $(\mathrm{c})]$ projected onto the paper plane by $d 2$. The interfaces are represented by dotted lines.

The ensuing question is how this interface lowers the Schottky barrier, which is rather difficult to investigate by experiment alone but can be suggested by calculations.

\section{ATOMISTIC CALCULATION RESULTS}

\section{A. Determination of interface atomic structure}

To clarify the mechanism theoretically, we first determined atomic structure of the $\mathrm{SiC} / \mathrm{Ti}_{3} \mathrm{SiC}_{2}$ interface via complementing the acquired HAADF image (Fig. 7). From the consideration of bulk structures of $4 \mathrm{H}-\mathrm{SiC}$ and $\mathrm{Ti}_{3} \mathrm{SiC}_{2}$, the aforementioned orientation relationships, and the relative stacking order of $\mathrm{Ti}$ and $\mathrm{Si}$, the observed image in Fig. 7 can be intuitively fitted by a SiSi model shown in Fig. 8(a). In this model, the interfacial $\mathrm{Si}$ atoms of $\mathrm{Ti}_{3} \mathrm{SiC}_{2}$ sit above the hollow sites of interfacial $\mathrm{Si}$ plane of $\mathrm{SiC}$, where the optimal distance between interfacial $\mathrm{Si}-\mathrm{Si}$ planes [denoted as $d 1$ in Fig. 8(a)] and that between interfacial $\mathrm{Si}-\mathrm{Si}$ atoms projected onto paper plane [denoted as $d 2$ in Fig. 8(a)] are calculated to be 2.13 and $2.53 \AA$ (Table I), respectively. These distances, however, deviate severely from their average experimental values, 2.5 and $2.8 \AA$, which are obtained by characterizing quantitatively the HAADF image (Fig. 7). In addition, an examination of interface stability by calculating adhesion energy $W_{\text {ad }}$, a key quantity to predict mechanical property of an interface, ${ }^{79,80}$ indicates that the SiSi model is

TABLE I. Relaxed $W_{\text {ad }}\left(\mathrm{J} / \mathrm{m}^{2}\right)$, optimal interfacial distances $d 1(\AA)$ and $d 2(\AA)$, and calculated $p$-type Schottky barrier heights $(\mathrm{SBH})(\mathrm{eV})$ for the $\mathrm{SiC} / \mathrm{Ti}_{3} \mathrm{SiC}_{2}$ interfaces without $(\mathrm{SiSi})$ and with interfacial $\mathrm{C}$ (SiCSi), and for the $\mathrm{SiC} / \mathrm{Ti}$ interface $(\mathrm{SiTi})$. Refer to Fig. 8 for their schematic configurations.

\begin{tabular}{lccc}
\hline \hline & SiSi & SiCSi & SiTi \\
\hline$W_{\text {ad }}\left(\mathrm{J} / \mathrm{m}^{2}\right)$ & 1.62 & 6.81 & 2.06 \\
$d 1(\AA)$ & 2.13 & 2.31 & 2.36 \\
$d 2(\AA)$ & 2.53 & 2.81 & 2.97 \\
$\mathrm{SBH}(\mathrm{eV})$ & 1.05 & 0.60 & 1.10 \\
\hline \hline
\end{tabular}

not favored $\left(1.62 \mathrm{~J} / \mathrm{m}^{2}\right)$. It is even less stable than the model with interfacial $\mathrm{Si}$ of $\mathrm{Ti}_{3} \mathrm{SiC}_{2}$ resting straight atop the interfacial $\mathrm{Si}$ of $\mathrm{SiC}\left(2.58 \mathrm{~J} / \mathrm{m}^{2}\right)$, which contravenes again the observed image. Why does the less preferred interface predicted by our simulations emerge in our experimental observation? It is worth mentioning that we have examined many other regions using the STEM but failed to see other possibilities.

Could these pronounced discrepancies between results of experiment and calculation be ascribed to computational inaccuracies? Since the calculation parameters described above are verified to be sufficient to ensure a total-energy precision of better than $1 \mathrm{meV} / \mathrm{atom}$, one might be concerned that another numerical inaccuracy arises from size effect of the used slabs. However, we found this inaccuracy to be within $0.1 \mathrm{~J} / \mathrm{m}^{2}$ via enlarging the slabs along the interface so that it does not affect our simulated $W_{\text {ad }}$. In addition, convergence tests show that the used slab thickness yields surface-energy convergence to smaller than $0.02 \mathrm{~J} / \mathrm{m}^{2}$. Furthermore, the used GGA was tested to evaluate bulk lattice constants and distances between atoms within an error of less than $0.5 \%{ }^{81,82}$ Finally, there is a small lattice mismatch of $0.63 \%$ at interface, ${ }^{34}$ which can be damped out by structural optimization. Moreover, Wang et al. ${ }^{83}$ have reported that a lattice mismatch as large as $3.9 \%$ at an interface varies the $W_{\text {ad }}$ only by less than $5 \%$. Therefore, it seems that the discrepancies should not simply be attributed to the computational error.

To resolve these paradoxes, we noticed that a possibility might be ignored, that is, the unseen $\mathrm{C}$ might be trapped at interface, altering the local environment there. To test this hypothesis, we established a model (named as SiCSi) by introducing $\mathrm{C}$ into the interfacial layer from the consideration of crystal extension and stacking sequences. The calculated $W_{\text {ad }}$ of this SiCSi model is listed in Table I, where one can see that the interface is strengthened substantially after the incorporation of C. Investigation into its fully optimized atomic configuration [Fig. 8(b)] reveals that the incorporation of $\mathrm{C}$ does not induce significant interface reconstruction. Namely, the two Si layers proximal to the interface maintain the stacking seen in Fig. 8(a), thus matching the HAADF image geometrically. Quantitatively, the $d 1$ and $d 2$ distances are now 2.53 and $2.81 \AA$ (see Table I), respectively, very close to the obtained experimental values. Therefore, the introduction of interfacial $\mathrm{C}$ monolayer resolves the inconsistencies between simulations and experiments. Finally, we superimpose the calculation-inferred atomic structure of SiCSi interface [Fig. 8(b)] onto the HAADF image [Fig. 7(a)] and find that they match very well.

\section{B. Schottky barrier height}

To further examine whether the determined interface has less Schottky character, we calculated $p$-type Schottky barrier height $(\mathrm{SBH})$, an important quantity in analyzing electric properties of a metal/semiconductor contact interface. ${ }^{84,85}$ The $p$-type $\mathrm{SBH}$ is calculated from the difference between the Fermi level $\left(E_{F}\right)$ of interface supercell and the valenceband top of bulk $\mathrm{SiC}$ region, ${ }^{86,87}$ which can be obtained by supercell calculations based on the DFT. It should be noted 


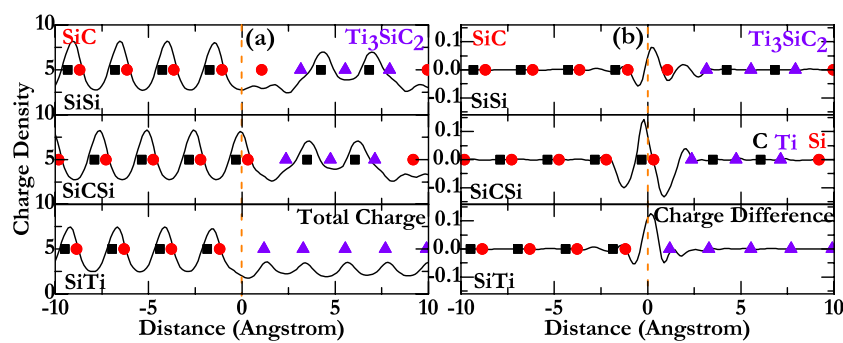

FIG. 9. (Color online) Planar-averaged (a) total charge density and (b) charge-density difference for the relaxed $\mathrm{SiSi}, \mathrm{SiCSi}$, and SiTi interfaces along [0001] direction. The solid rectangles, circles, and triangles give the locations of $\mathrm{C}, \mathrm{Si}$, and $\mathrm{Ti}$ atoms, respectively. The interface position is set to zero and indicated by a vertical line.

that due to the well-known problem of discontinuity in the exchange-correlation potential across heterointerface, ${ }^{88,89}$ an exact quantitative estimation of SBH is unlikely. However, qualitative comparisons between the calculated SBHs for different interface configurations should be reliable. ${ }^{90,91}$ The $p$-type $\mathrm{SBH}$ for the $\mathrm{SiC} / \mathrm{Ti}_{3} \mathrm{SiC}_{2}$ interfaces with and without interfacial $\mathrm{C}$ are listed in Table I, where the $\mathrm{SBH}$ for the $\mathrm{SiC} / \mathrm{Ti}$ interface [Fig. 8(c)] is listed as well for comparison (denoted as SiTi in Table I). From this table, one can see that the SiCSi interface shows the lowest SBH, meaning that it is of the least Schottky nature. Since no theoretical SBH values for the $\mathrm{SiC} / \mathrm{Ti}_{3} \mathrm{SiC}_{2}$ interface are available and direct comparison of our calculated values with experimental data is complicated, it is hard to verify the accuracy of our results directly. However, we have noted that our simulated SBH of the SiTi case $(1.10 \mathrm{eV})$ agrees well with the $\mathrm{SBH}$ of $1.00 \mathrm{eV}$ calculated from the $6 \mathrm{H}-\mathrm{SiC} / \mathrm{Ti}$ interface. ${ }^{86}$

\section{Electronic structure and bonding}

\section{Planar-averaged charge density}

To shed light on origin of decrease in SBH and junction strengthening in the SiCSi interface, we applied several analytic approaches to characterize in detail interfacial electronic states and bonding nature. First, we calculated planaraveraged charge density and its difference along the interface normal. The density difference is evaluated by subtracting the sum of charge density of isolated $\mathrm{SiC}$ and $\mathrm{Ti}_{3} \mathrm{SiC}_{2}$ slabs from the total interface charge density. ${ }^{80}$ As seen in Fig. 9(a), after introducing the $\mathrm{C}$, an interfacial $\mathrm{Si}-\mathrm{C}$ pair is generated in the SiCSi case in a way similar to the pair in bulk SiC. As a result of the pair, there is a dramatic accumulation of charge within the interfacial region, in contrast to what is seen in either the SiSi or SiTi interface [Fig. 9(a)]. This indicates that the covalent bonding is strengthened for the SiCSi. Evidently, the large degree of charge accumulation at interface is at the expense of depletion of charge in the subinterfacial layers between $\mathrm{Si}$ and $\mathrm{Ti}$, suggestive of weakened bonding between them. This is a short-range effect, however, since the charge density returns to its bulk value by the second layer. From Fig. 9(b), we note that the planar-averaged density difference for the SiCSi most prominently deviates from zero around the interface, reflecting the most significant charge transfer between $\mathrm{SiC}$ and $\mathrm{Ti}_{3} \mathrm{SiC}_{2}$ slabs. In addition,
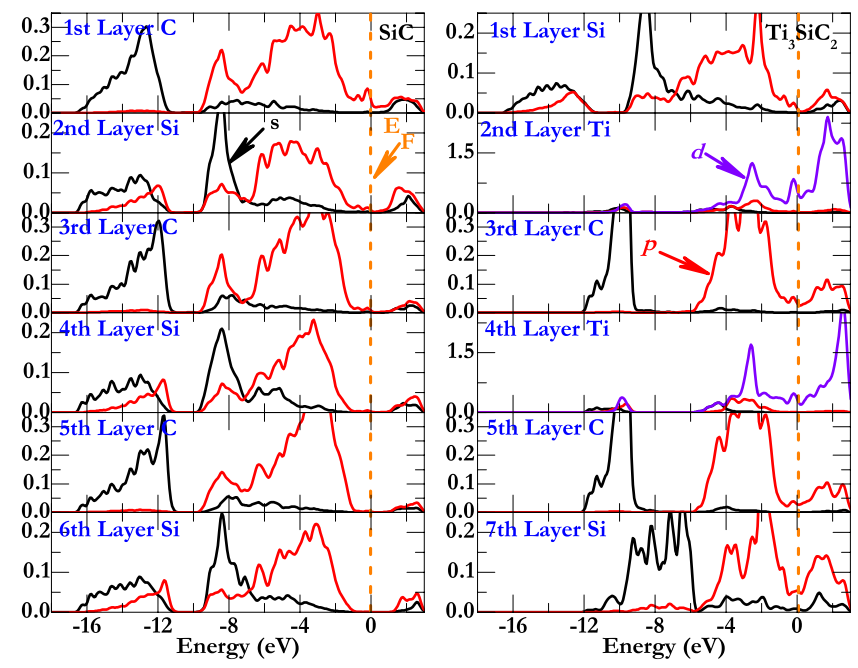

FIG. 10. (Color online) DOS (states/eV atom) projected on the atomic layers close to the relaxed SiCSi interface. The left panel shows PDOSs of $\mathrm{SiC}$ layers and the right one those of $\mathrm{Ti}_{3} \mathrm{SiC}_{2}$ layers. The first layer is the atomic layer proximal to interface. The $E_{F}$ is set to zero and marked by a dashed line.

charge is observed to be depleted noticeably in both the subinterfacial $\mathrm{SiC}$ and $\mathrm{Ti}_{3} \mathrm{SiC}_{2}$ region for the $\mathrm{SiCSi}$, suggesting that the atoms second nearest to the interface contribute to the interfacial bonding. These missing charges, to a large extent, make their way onto the more electronegative $\mathrm{C}$ ions, indicative of formation of ionic bonding.

\section{Partial density of states}

We then presented in Fig. 10 the density of states (DOS) projected on selected atomic layers of the SiCSi interface in order to gain insight into the electronic states. As seen in this figure, the overall partial DOS (PDOS) shape of interfacial $\mathrm{Si}$ of $\mathrm{Ti}_{3} \mathrm{SiC}_{2}$ resembles to some extent that of a $\mathrm{Si}$ layer deeper in $\mathrm{SiC}$ but deviates remarkably from that of a $\mathrm{Si}$ layer deeper in $\mathrm{Ti}_{3} \mathrm{SiC}_{2}$ (seventh layer), which can be reflected from the formation of $\mathrm{Si}-\mathrm{C}$ pair. Moreover, this suggests that the substrate has a fundamental effect on interface electronically. A key feature in this figure is that a strong interaction is observed between the subinterfacial Ti $d$ and Si $p$ states below $E_{F}$, which continues well into the $\mathrm{SiC}$ surface, inducing noticeable gap states in the interfacial $C$ at $E_{F}$. This means that the interfacial $\mathrm{C}$ layer, the first monolayer on the substrate, is metallized, indicative of possible electric conductivity. In fact, the gap states can extend as far as they can into deeper layers of $\mathrm{SiC}$, as there appear weak but visible peaks at $E_{F}$ in the PDOSs of the second and third layers of SiC. Consequently, a local weak metallicity might occur in top few layers of the semiconductor surface, which could enable current flow through the $\mathrm{SiC}$. Apart from the peaks in $\mathrm{SiC}$, all of the $\mathrm{Ti}_{3} \mathrm{SiC}_{2}$ layers exhibit notable peaks at $E_{F}$, which can be attributed to the large degree of overlap between Ti $d$ and $\mathrm{C}(\mathrm{Si}) p$ states. Finally, we note significant hybridization between the interfacial $\mathrm{C} s p$ and $\mathrm{Si} s p$ states, suggestive of covalent bonding at interface.

\section{Charge distribution}

To identify the bonding type directly, we further show contour plots of charge densities (Fig. 11) and their differ- 

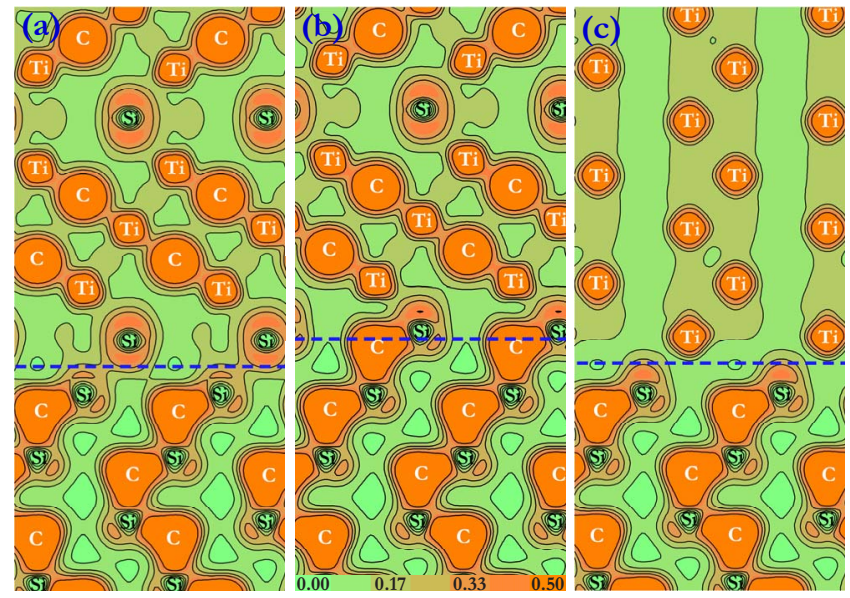

FIG. 11. (Color online) Contour plots of charge densities for (a) $\mathrm{SiSi}$, (b) SiCSi, and (c) SiTi interfaces taken along the (11200) plane. The interface is represented by a horizontal line and the atoms that intersect the contour plane are labeled. The magnitude of charge is denoted by a scale at the bottom of (b).

ences (Fig. 12) along the (1120) plane for the optimized $\mathrm{SiSi}, \mathrm{SiCSi}$, and SiTi interfaces. From Fig. 11, we notice first that the bonding interaction between the interfacial $\mathrm{Si}$ and $\mathrm{C}$ for the SiCSi interface is remarkably similar to the $\mathrm{Si}-\mathrm{C}$ interaction deeper into $\mathrm{SiC}$ : the majority of charge is localized on $\mathrm{C}$ with humps directed toward their adjacent $\mathrm{Si}$. We thus conclude that the interfacial bonding for the SiCSi is of mixed covalent-ionic nature. The interfacial bonds for the $\mathrm{SiSi}$ interface, however, exhibit covalent character with a small amount of charge accumulated within the interfacial region [Fig. 11(a)], in consistence with our analyses on planar-averaged density difference (Fig. 9). As for the SiTi, the charge distribution of interfacial $\mathrm{Ti}$ is almost identical to that of Ti away from interface, having a character of weakly but broadly distributed charge density. This indicates that the interfacial bonds for the SiTi take on weakly metallic nature, yet maintain a small degree of covalency. The covalency can

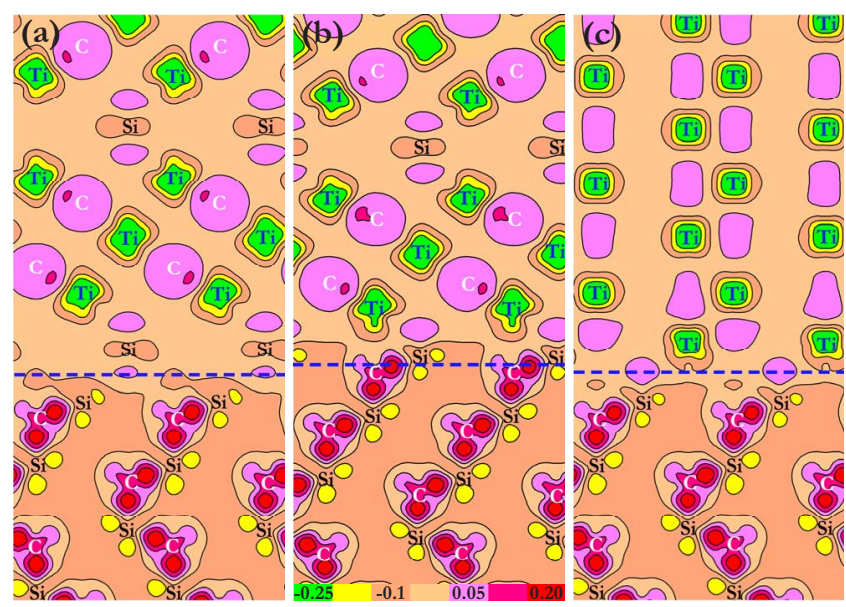

FIG. 12. (Color online) Contour plots of charge-density differences for (a) SiSi, (b) SiCSi, and (c) SiTi interfaces taken along the $(1 \overline{12} 0)$ plane. The difference of charge density presents redistribution of charge in the interface relative to its isolated system.

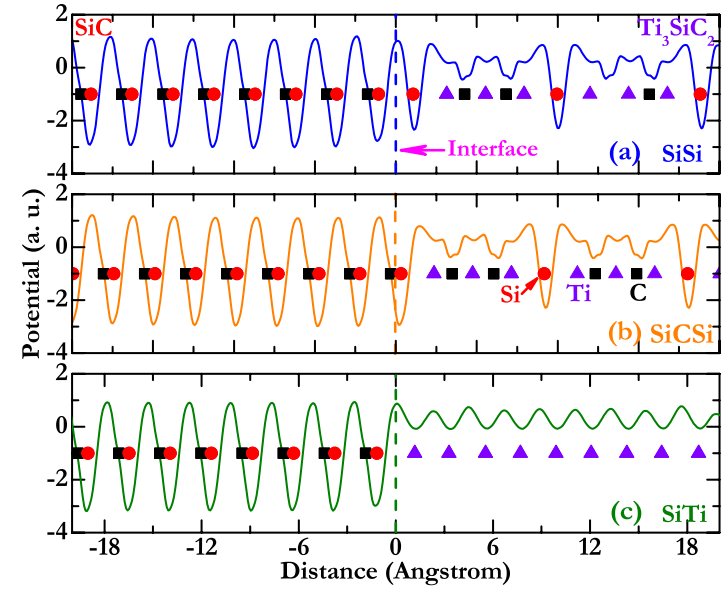

FIG. 13. (Color online) Electrostatic potential as a function of distance from interface along the [0001] direction for (a) $\mathrm{SiSi}$, (b) $\mathrm{SiCSi}$, and (c) SiTi interfaces. Interface position is set to zero.

be further confirmed from the density-difference plot [Fig. 12(c)] displaying charge accumulation along the interfacial $\mathrm{Si}-\mathrm{Ti}$ bonds. The amount of charge accumulated on the $\mathrm{Si}-\mathrm{Ti}$ bonds is larger than that on the interfacial $\mathrm{Si}-\mathrm{Si}$ bonds of $\mathrm{SiSi}$ [Fig. 12(a)] but far less significant than that on the interfacial Si-C bonds of SiCSi [Fig. 12(b)]. This heaviest charge accumulation along the interfacial Si-C bonds, together with the mixed covalent-ionic character at the SiCSi interface, explains the largest $W_{\mathrm{ad}}$ associated with the SiCSi interface (Table I). Finally, we note from both figures that charge variations due to interface are screened rapidly with distance from interface, suggesting that the interface effect is confined within a short range, in good agreement with our previous analyses on PDOS and planar-averaged charge.

\section{Electrostatic potential}

To further explain the decrease in $\mathrm{SBH}$ for the $\mathrm{SiCSi}$, we plotted the variation in electrostatic potential along the interface normal in Fig. 13, where potential changes for the SiSi and SiTi interfaces are shown as well for comparison. As a result of the large interface dipole generated by the considerable charge transfer [Fig. 9(b)] and the partial ionicity [Fig. 11(b)], the electrostatic potential of interfacial $\mathrm{Si}$ in the SiCSi is lowered significantly relative to its adjacent $\mathrm{SiC}$ region [Fig. 13(b)], which consequently enables the reduction in SBH. This is contrary to the SiSi [Fig. 13(a)] and SiTi [Fig. 13(c)] cases, as their electrostatic potentials are high at interface. These high potentials indicate that electrons might be transferred from the $\mathrm{SiC}$ surface to the interface, resulting in electron depletion on substrate surface. Moreover, we note in Fig. 13 that electrostatic potential for $\mathrm{Si}$ atoms is always lower than that for the $\mathrm{Ti}$ or $\mathrm{C}$ atoms, which explains the lower electron density of $\mathrm{Si}$ shown in the charge-distribution plot (Fig. 11).

\section{Electron density near Fermi level}

Although the charge-distribution analysis can reveal valuable information on interfacial bonding, it provides re- 

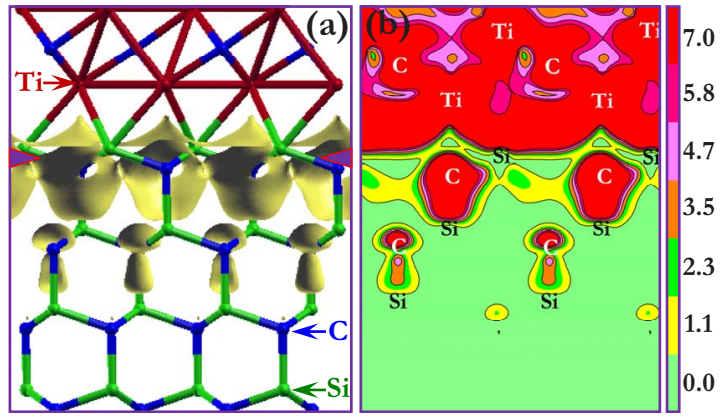

FIG. 14. (Color online) (a) Isosurface and (b) electron-density plot along the $(11 \overline{2} 0)$ plane in the energy window $\left(E_{F}-0.5 \mathrm{eV}, E_{F}\right)$ for the SiCSi interface. The interface is marked by two arrows.

strained insight into how electrons distribute around $E_{F}$, which matters because density around $E_{F}$ directly determines the current transmission. Figure 14 illustrates an electrondensity isosurface and its slice along the $(11 \overline{2} 0)$ plane for the optimized SiCSi interface around $E_{F}$. From Fig. 14(a), one can see that charges surrounding interfacial Si are connected and broadly distributed in a sheetlike fashion, which suggests possible electrical conductivity through this region. In addition, there also appear heavily accumulated electrons within the interfacial area, which are connected along the interface and extended as far as several atomic layers into the SiC. These characters can also be confirmed from the slice plot in Fig. 14(b), meaning that current might flow over top few atomic layers of semiconductor, thereby causing ohmic property. As expected, the electron density at $E_{F}$ is extremely high for the $\mathrm{Ti}_{3} \mathrm{SiC}_{2}$ (i.e., sea of electrons) but becomes nil for the SiC layers away from interface [Fig. 14(b)], which can be understood from their intrinsic metallic and semiconducting nature. ${ }^{92,93}$

\section{E. Quantum electron transport properties}

To examine electrical conductivity and gain insight into how the interface influences current transport, we devised a two-probe system, $\mathrm{Ti} / \mathrm{Ti}_{3} \mathrm{SiC}_{2} / \mathrm{SiC} / \mathrm{Ti}_{3} \mathrm{SiC}_{2} / \mathrm{Ti}$, and investigated nonequilibrium quantum transport properties. Figure 15 schematically shows a model of the sandwich transport system, which can be divided into a left semi-infinite electrode, a scattering region, and a right semi-infinite electrode..$^{57,94}$ The atomic and electronic structures of the semi-infinite Ti electrodes are assumed to be the same as

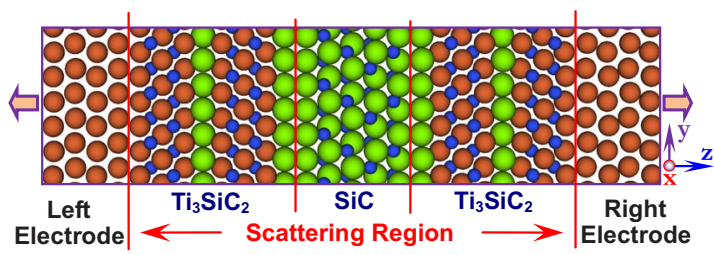

FIG. 15. (Color online) Schematic illustration of a two-probe $\mathrm{Ti} / \mathrm{Ti}_{3} \mathrm{SiC}_{2} / \mathrm{SiC} / \mathrm{Ti}_{3} \mathrm{SiC}_{2} / \mathrm{Ti}$ quantum transport system. The system has infinite extent in the $(x, y)$ direction and extends to $\pm \infty$ in the $z$ direction. The $\mathrm{SiC} / \mathrm{Ti}_{3} \mathrm{SiC}_{2}$ interfaces shown in Fig. 8 are adopted.

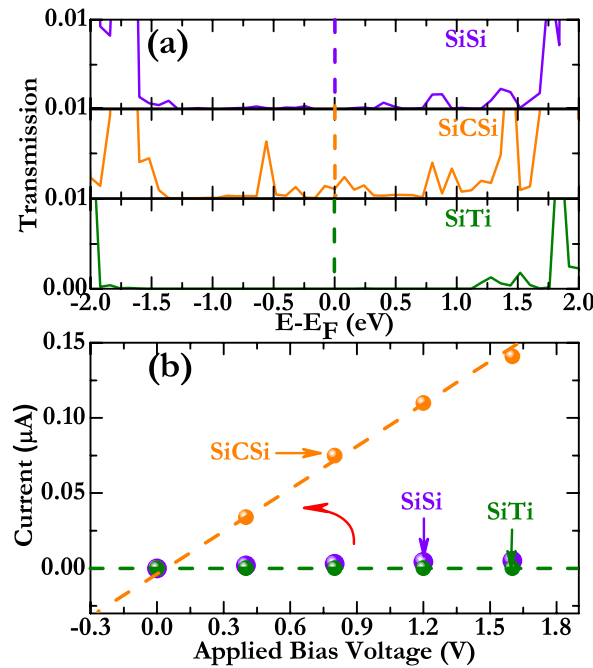

FIG. 16. (Color online) (a) Transmission spectra under $0 \mathrm{~V}$ and (b) current-voltage characteristics for the sandwich systems involving the SiSi, SiCSi, and SiTi interface. Refer to Fig. 8 for their corresponding interfacial configurations.

those of bulk Ti. On the other hand, the electronic states of scattering region are calculated self-consistently. The scattering region consists of hexagonal $\mathrm{SiC}$ and $\mathrm{Ti}_{3} \mathrm{SiC}_{2}$ layers and the periodic boundary conditions are imposed along the directions parallel to the interface. The $\mathrm{SiC} / \mathrm{Ti}_{3} \mathrm{SiC}_{2}$ interface could be either the $\mathrm{SiSi}$ or $\mathrm{SiCSi}$, whereas other interfaces are maintained identical for the sandwich systems. In this sense, the difference between the two systems can be mainly attributed to their differing $\mathrm{SiC} / \mathrm{Ti}_{3} \mathrm{SiC}_{2}$ interfaces. Furthermore, we also calculated the $\mathrm{Ti} / \mathrm{SiC} / \mathrm{Ti}$ system, wherein the SiTi model shown in Fig. 8(c) was taken as the SiC/Ti interface.

Figure 16(a) shows transmission spectra for the relaxed $\mathrm{SiSi}, \mathrm{SiCSi}$, and SiTi systems, where one can see that the spectra differ from one another suggesting variations in electronic structures with interface geometries. The most interesting feature is the presence of transmission peaks at $E_{F}$ for the $\mathrm{SiCSi}$, which is attributable to the electrons distributed around the interface at $E_{F}$. Further calculations on electrical properties (e.g., $I-V$ curve) for the three systems reveal that the current in the SiCSi case increases much faster than either the $\mathrm{SiSi}$ or SiTi case as the applied bias voltage increases [Fig. 16(b)], which can be explained by its lowest SBH (Table I). Finally, in comparing the general trend of the calculated $I-V$ with that of our experimental curve (Fig. 1), we find that they agree qualitatively: both the annealed specimen and the SiCSi model clearly show ohmic behavior, thereby validating the application of the SiCSi model to describe the ohmic contacts in the TiAl-based system.

\section{DISCUSSION AND CONCLUSIONS}

Although a number of works have been conducted on the TiAl-based ohmic contact, its mechanism remains controversial. The current understanding of its formation origin, which is based mainly on experimental studies of property mea- 
surement and structure characterization, can be summarized in three main points: (1) the deposited $\mathrm{Al}$ (80 at. \%) might diffuse in part into the $\mathrm{SiC}$ and dope heavily the semiconductor because the $\mathrm{Al}$ is well known to act as a $p$-type dopant for $\mathrm{SiC},{ }^{28,67}$ (2) the high density of pits, spikes, or dislocations may be generated underneath the contacts after annealing so that current can transport primarily through these defects due to the possible enhancement of electric field at these features and semiconductor doping at these locations, and ${ }^{27,95}$ (3) the formation of intermediate semiconductor layer between the deposited metals and semiconductor, which consists of silicides or carbides, could divide the high barrier height into lower ones, thus reducing the effective barrier height. ${ }^{29,32}$

The results presented in this paper first demonstrate that no $\mathrm{Al}$ is clearly segregated around the interfacial region, in particular, at the top few layers of $\mathrm{SiC}$, which rules out the possibility of additional Al doping. ${ }^{29,73}$ Though a small amount of residual $\mathrm{Al}$ is found to be present, mostly in form of $\mathrm{Al}_{4} \mathrm{C}_{3}$ compound, it may locate on the surface of annealed contacts rather than in the layer directly contacted to the SiC, thus playing a negligible role in ohmic contact formation. The majority of deposited $\mathrm{Al}$ is evaporated during annealing because of its low melting point and high equilibrium vapor pressure. The dominant role played by $\mathrm{Al}$ in the TiAl system is to assist the formation of liquid alloy so as to facilitate chemical reaction. ${ }^{73}$ Furthermore, careful characterization of the interfacial region reveals that the substrate and the generated compound are epitaxially oriented and well matched at interface with no clear evidence of high density of defects. This suggests that the morphology might not be the key to understanding the contact formation. ${ }^{29}$ In support of this speculation, it has been observed previously that $\mathrm{Ti}$ ohmic contacts can be possibly generated without any pitting and that pit-free ohmic contacts can be fabricated. ${ }^{25,96}$

One remaining theory is the alloy-assisted ohmic contact formation. ${ }^{30,33}$ This alloy is determined to be ternary $\mathrm{Ti}_{3} \mathrm{SiC}_{2}$ in our study, which has also been corroborated by other experiments. ${ }^{29,73}$ Since the bulk $\mathrm{Ti}_{3} \mathrm{SiC}_{2}$ has already been found to be of metallic nature both in experiment and theory, ${ }^{97,98}$ the contact between $\mathrm{Ti}_{3} \mathrm{SiC}_{2}$ and its covered metals should show ohmic character and thus the $\mathrm{SiC} / \mathrm{Ti}_{3} \mathrm{SiC}_{2}$ interface should play a significant role in ohmic contact formation. Our calculation results support this idea by suggesting that the determined interface has a lowered SBH due to the large dipole shift at interface induced by the partial ionicity and the considerable charge transfer. In addition, the interfacial states, as indicated by the electron distribution at $E_{F}$, are also viewed as a contributing factor in reducing the $\mathrm{SBH}$. These states might be further enhanced by the possible presence of point defects at interface, although these structural defects have not been detected by our TEM and addressed in this study.

Interestingly, our calculations predict that an atomic layer of carbon emerges as the first monolayer of ohmic contacts, which eventually affects interface electronic structure. Such trapped carbon was previously studied in both other interfacial systems theoretically by DFT (Ref. 83) and the TiNi ohmic contacts on $4 \mathrm{H}-\mathrm{SiC}$ experimentally by Auger electron spectroscopy. ${ }^{31}$ It was proposed that the carbon could be segregated to the interfacial area, strengthening interface substantially and reducing the Schottky barrier dramatically. ${ }^{83,87}$ Further, it was reported that the ohmic contact can be realized by depositing carbon films only onto the $\mathrm{SiC}$ substrate, indicative of the determinative role of carbon in the ohmic contact formation. ${ }^{99}$ The important role played by carbon in our study can be traced to the two interfacial Si layers, which provide possible sites for carbon segregation due to the strong Si-C interaction. However, direct imaging of the trapped carbon is still difficult in present study and further characterization requires the high-voltage EM and/or other advanced microscopic techniques. ${ }^{100,101}$

Several experimental methods can be used to probe the ohmic character of $\mathrm{Ti}_{3} \mathrm{SiC}_{2}$ contacts on $\mathrm{SiC}$ discussed in this paper. For example, based on our results regarding the morphology of grown layers, epitaxial $\mathrm{Ti}_{3} \mathrm{SiC}_{2}$ layers can be deposited directly onto the $\mathrm{SiC}$ substrate by means of sputtering, molecular-beam epitaxy (MBE), or pulsed-laser deposition (PLD). In particular, the crucial effect of interfacial carbon can be possibly examined using the MBE and PLD techniques, which allow layer-by-layer deposition of crystalline thin films. ${ }^{102,103}$ If the outcome of such investigations is positive for ohmic contact formation, direct deposition of epitaxial $\mathrm{Ti}_{3} \mathrm{SiC}_{2}$ thin films rather than the metals would be a potential processing technique for easier realization of ordered structure and better control of ohmic property.

To summarize, we have determined atomic-scale structure of ohmic contacts on $\mathrm{SiC}$ and related it to electronic structure and electric property, aimed at understanding the formation mechanism of ohmic contact in TiAl-based system. The combined HAADF-DFT study we performed represents an important advance for relating structure to device property at atomic scale and is not limited to the contacts in SiC electronics. Our results show that the main product generated by chemical reaction can be epitaxial and have atomic bonds to the substrate. The contact interface, which could trap an atomic layer of carbon, enables lowered Schottky barrier due to the large interfacial dipole shift associated with the considerable charge transfer. These findings are relevant for technological improvement of contacts in SiC devices, and this paper presents an important step toward addressing the current contact issues in wide-band-gap electronics.

\section{ACKNOWLEDGMENTS}

We thank S. Watanabe (University of Tokyo) for allowing our use of computational resources. The present study was supported in part by a Grant-in-Aid for Scientific Research on Priority Area, "Atomic Scale Modification (474)" from the Ministry of Education, Culture, Sports, Science, and Technology of Japan. One of the authors (S.T.) also acknowledges the financial support from The Murata Science Foundation. The calculations were carried out on a parallel SR11000 supercomputer at the Institute for Solid State Physics, University of Tokyo. 
*zcwang@wpi-aimr.tohoku.ac.jp

${ }^{1}$ H. Morkoç, S. Strite, G. B. Gao, M. E. Lin, B. Sverdlov, and M. Burns, J. Appl. Phys. 76, 1363 (1994).

${ }^{2}$ M. W. Cole, P. C. Joshi, C. W. Hubbard, M. C. Wood, M. H. Ervin, and B. Geil, J. Appl. Phys. 88, 2652 (2000).

${ }^{3}$ K. Shenai, R. S. Scott, and B. J. Baliga, IEEE Trans. Electron Devices 36, 1811 (1989).

${ }^{4}$ T. P. Chow, V. Khemka, J. Fedison, N. Ramungul, K. Matocha, Y. Tang, and R. J. Gutmann, Solid-State Electron. 44, 277 (2000).

${ }^{5}$ B. Baumeier, P. Krüger, and J. Pollmann, Phys. Rev. B 73, 195205 (2006).

${ }^{6}$ P. G. Neudeck, J. Electron. Mater. 24, 283 (1995).

${ }^{7}$ R. J. Trew, Phys. Status Solidi A 162, 409 (1997).

${ }^{8}$ C. E. Weitzel, IEEE Electron Device Lett. 16, 451 (1995).

${ }^{9}$ R. R. Siergiej, R. C. Clarke, S. Sriram, A. K. Agarwal, R. J. Bojko, A. W. Morse, V. Balakrishna, M. F. MacMillan, A. A. Burk, Jr., and C. D. Brandt, Mater. Sci. Eng., B 61-62, 9 (1999).

${ }^{10}$ L. M. Porter and R. F. Davis, Mater. Sci. Eng., B 34, 83 (1995).

${ }^{11}$ I. Perez-Wurfl, R. Krutsinger, J. T. Torvik, and B. Van Zeghbroeck, Solid-State Electron. 47, 229 (2003).

${ }^{12}$ V. Heera, D. Panknin, and W. Skorupa, Appl. Surf. Sci. 184, 307 (2001).

${ }^{13}$ S.-K. Lee, C.-M. Zetterling, E. Danielsson, M. Östling, J.-P. Palmquist, H. Högberg, and U. Jansson, Appl. Phys. Lett. 77, 1478 (2000).

${ }^{14}$ B. Pécz, Appl. Surf. Sci. 184, 287 (2001).

${ }^{15}$ M. Murakami, Sci. Technol. Adv. Mater. 3, 1 (2002).

${ }^{16}$ H. Yang, T. H. Peng, W. J. Wang, D. F. Zhang, and X. L. Chen, Appl. Surf. Sci. 254, 527 (2007).

${ }^{17}$ I. P. Nikitina, K. V. Vassilevski, N. G. Wright, A. B. Horsfall, A. G. O’Neill, and C. M. Johnson, J. Appl. Phys. 97, 083709 (2005).

${ }^{18}$ S.-K. Lee, C.-M. Zetterling, M. Östling, J.-P. Palmquist, H. Högberg, and U. Jansson, Solid-State Electron. 44, 1179 (2000).

${ }^{19}$ B. T. Lee, J. Y. Shin, S. H. Kim, J. H. Kim, S. Y. Han, and J. L. Lee, J. Electron. Mater. 32, 501 (2003).

${ }^{20}$ W. Lu, W. C. Mitchel, G. R. Landis, T. R. Crenshaw, and W. Eugene Collins, Solid-State Electron. 47, 2001 (2003).

${ }^{21}$ B. Barda, P. Macháč, M. Hubičková, and J. Náhlík, J. Mater. Sci.: Mater. Electron. 19, 1039 (2008).

${ }^{22}$ J. H. Park and P. H. Holloway, J. Vac. Sci. Technol. B 23, 486 (2005).

${ }^{23} \mathrm{~K}$. Vassilevski, K. Zekentes, K. Tsagaraki, G. Constantinidis, and I. Nikitina, Mater. Sci. Eng., B 80, 370 (2001).

${ }^{24}$ J. Crofton, P. A. Barnes, J. R. Williams, and J. A. Edmond, Appl. Phys. Lett. 62, 384 (1993).

${ }^{25}$ J. Crofton, L. Beyer, J. R. Williams, E. D. Luckowski, S. E. Mohney, and J. M. Delucca, Solid-State Electron. 41, 1725 (1997).

${ }^{26}$ B. Veisz and B. Pécz, Appl. Surf. Sci. 233, 360 (2004).

${ }^{27}$ S. E. Mohney, B. A. Hull, J. Y. Lin, and J. Crofton, Solid-State Electron. 46, 689 (2002).

${ }^{28}$ O. Nakatsuka, T. Takei, Y. Koide, and M. Murakami, Mater. Trans. 43, 1684 (2002).

${ }^{29}$ B. J. Johnson and M. A. Capano, J. Appl. Phys. 95, 5616 (2004).

${ }^{30}$ S.-C. Chang, S.-J. Wang, K.-M. Uang, and B.-W. Liou, SolidState Electron. 49, 1937 (2005).

${ }^{31}$ T. Ohyanagi, Y. Onose, and A. Watanabe, J. Vac. Sci. Technol. B 26, 1359 (2008).
${ }^{32}$ S. Tsukimoto, K. Nitta, T. Sakai, M. Moriyama, and M. Murakami, J. Electron. Mater. 33, 460 (2004).

${ }^{33}$ S. Tsukimoto, T. Sakai, and M. Murakami, J. Appl. Phys. 96, 4976 (2004).

${ }^{34}$ Z. Wang, S. Tsukimoto, M. Saito, and Y. Ikuhara, Phys. Rev. B 79, 045318 (2009).

${ }^{35}$ P. D. Nellist, M. F. Chisholm, N. Dellby, O. L. Krivanek, M. F. Murfitt, Z. S. Szilagyi, A. R. Lupini, A. Borisevich, W. H. Sides, Jr., and S. J. Pennycook, Science 305, 1741 (2004).

${ }^{36}$ M. Haider, H. Rose, S. Uhlemann, B. Kabius, and K. Urban, Nature (London) 392, 768 (1998).

${ }^{37}$ A. Ziegler, J. C. Idrobo, M. K. Cinibulk, C. Kisielowski, N. D. Browning, and R. O. Ritchie, Science 306, 1768 (2004).

${ }^{38}$ J. P. Buban, K. Matsunaga, J. Chen, N. Shibata, W. Y. Ching, T. Yamamoto, and Y. Ikuhara, Science 311, 212 (2006).

${ }^{39}$ C. J. Först, C. R. Ashman, K. Schwarz, and P. E. Blöchl, Nature (London) 427, 53 (2004)

${ }^{40}$ D. O. Demchenko and A. Y. Liu, Phys. Rev. B 73, 115332 (2006).

${ }^{41}$ T. J. Zega, A. T. Hanbicki, S. C. Erwin, I. Žutić, G. Kioseoglou, C. H. Li, B. T. Jonker, and R. M. Stroud, Phys. Rev. Lett. 96, 196101 (2006).

${ }^{42}$ C. I. Carlisle, D. A. King, M. L. Bocquet, J. Cerda, and P. Sautet, Phys. Rev. Lett. 84, 3899 (2000).

${ }^{43}$ Z. J. Lin, M. J. Zhuo, Y. C. Zhou, M. S. Li, and J. Y. Wang, Scr. Mater. 55, 445 (2006).

${ }^{44}$ C. Persson and U. Lindefelt, Phys. Rev. B 54, 10257 (1996).

${ }^{45}$ N. W. Jepps and T. F. Page, Prog. Cryst. Growth Charact. 7, 259 (1983).

${ }^{46}$ S. Tsukimoto, K. Ito, Z. Wang, M. Saito, Y. Ikuhara, and M. Murakami, Mater. Trans. 50, 1071 (2009).

${ }^{47}$ J. Crofton, S. E. Mohney, J. R. Williams, and T. Isaacs-Smith, Solid-State Electron. 46, 109 (2002).

${ }^{48}$ S. J. Pennycook and L. A. Boatner, Nature (London) 336, 565 (1988).

${ }^{49}$ G. Kresse and J. Furthmüller, Phys. Rev. B 54, 11169 (1996).

${ }^{50}$ G. Kresse and J. Hafner, Phys. Rev. B 47, 558 (1993).

${ }^{51}$ P. E. Blöchl, Phys. Rev. B 50, 17953 (1994).

${ }^{52}$ J. P. Perdew, J. A. Chevary, S. H. Vosko, K. A. Jackson, M. R. Pederson, D. J. Singh, and C. Fiolhais, Phys. Rev. B 46, 6671 (1992).

${ }^{53}$ H. J. Monkhorst and J. D. Pack, Phys. Rev. B 13, 5188 (1976).

${ }^{54}$ B. Baumeier, P. Krüger, and J. Pollmann, Phys. Rev. B 78, 245318 (2008)

${ }^{55}$ M. C. Payne, M. P. Teter, D. C. Allan, T. A. Arias, and J. D. Joannopoulos, Rev. Mod. Phys. 64, 1045 (1992).

${ }^{56}$ R. P. Feynman, Phys. Rev. 56, 340 (1939).

${ }^{57}$ M. Brandbyge, J. Mozos, P. Ordejón, J. Taylor, and K. Stokbro, Phys. Rev. B 65, 165401 (2002).

${ }^{58}$ J. M. Soler, E. Artacho, J. D. Gale, A. García, J. Junquera, P. Ordejón, and D. Sánchez-Portal, J. Phys.: Condens. Matter 14, 2745 (2002).

${ }^{59}$ Z. Wang, T. Kadohira, T. Tada, and S. Watanabe, Nano Lett. 7 , 2688 (2007).

${ }^{60}$ Z. Wang, T. Gu, T. Tada, and S. Watanabe, Appl. Phys. Lett. 93, 152106 (2008).

${ }^{61}$ J. Taylor, H. Guo, and J. Wang, Phys. Rev. B 63, 245407 (2001).

${ }^{62}$ J. Taylor, M. Brandbyge, and K. Stokbro, Phys. Rev. Lett. 89, 138301 (2002).

${ }^{63}$ N. Troullier and J. L. Martins, Phys. Rev. B 43, 1993 (1991). 
${ }^{64}$ Th. Seyller, K. V. Emtsev, F. Speck, K.-Y. Gao, and L. Ley, Appl. Phys. Lett. 88, 242103 (2006).

${ }^{65}$ K. Ito, T. Onishi, H. Takeda, K. Kohama, S. Tsukimoto, M. Konno, Y. Suzuki, and M. Murakami, J. Electron. Mater. 37, 1674 (2008).

${ }^{66}$ J. Wan, M. A. Capano, and M. R. Melloch, Solid-State Electron. 46, 1227 (2002).

${ }^{67}$ J. Crofton, L. M. Porter, and J. R. Williams, Phys. Status Solidi B 202, 581 (1997).

${ }^{68}$ F. A. Mohammad, Y. Cao, and L. M. Porter, Appl. Phys. Lett. 87, 161908 (2005).

${ }^{69}$ S. Tsukimoto, T. Sakai, T. Ohishi, K. Ito, and M. Murakami, J. Electron. Mater. 34, 1310 (2005).

${ }^{70}$ B. Pécz, L. Tóth, M. A. di Forte-Poisson, and J. Vacas, Appl. Surf. Sci. 206, 8 (2003).

${ }^{71}$ J. C. Viala, N. Peillon, F. Bosselet, and J. Bouix, Mater. Sci. Eng., A 229, 95 (1997).

${ }^{72}$ M. R. Jennings, A. Pérez-Tomás, M. Davies, D. Walker, L. Zhu, P. Losee, W. Huang, S. Balachandran, O. J. Guy, J. A. Covington, T. P. Chow, and P. A. Mawby, Solid-State Electron. 51, 797 (2007).

${ }^{73}$ M. Gao, S. Tsukimoto, S. H. Goss, S. P. Tumakha, T. Onishi, M. Murakami, and L. J. Brillson, J. Electron. Mater. 36, 277 (2007).

${ }^{74}$ R. T. M. Ummels, P. A. Bobbert, and W. van Haeringen, Phys. Rev. B 58, 6795 (1998).

${ }^{75}$ A. Bauer, J. Kraublich, L. Dressler, P. Kuschnerus, J. Wolf, and K. Goetz, Phys. Rev. B 57, 2647 (1998).

${ }^{76}$ M. Y. Gamarnik and M. W. Barsoum, J. Mater. Sci. 34, 169 (1999).

${ }^{77}$ T. Goto and T. Hirai, Mater. Res. Bull. 22, 1195 (1987).

${ }^{78}$ Y. Sato, J. P. Buban, T. Mizoguchi, N. Shibata, M. Yodogawa, T. Yamamoto, and Y. Ikuhara, Phys. Rev. Lett. 97, 106802 (2006).

${ }^{79}$ W. Liu, J. C. Li, W. T. Zheng, and Q. Jiang, Phys. Rev. B 73, 205421 (2006).

${ }^{80}$ K. Nagao, J. B. Neaton, and N. W. Ashcroft, Phys. Rev. B 68, 125403 (2003).

${ }^{81}$ Z. Wang, T. Gu, T. Kadohira, T. Tada, and S. Watanabe, J. Chem. Phys. 128, 014704 (2008).

${ }^{82}$ J. R. Smith and W. Zhang, Acta Mater. 48, 4395 (2000).
${ }^{83}$ X. Wang, J. R. Smith, and A. Evans, Phys. Rev. Lett. 89, 286102 (2002).

${ }^{84}$ S. N. Rashkeev, W. R. L. Lambrecht, and B. Segall, Phys. Rev. B 55, 16472 (1997).

${ }^{85}$ G. Profeta, A. Blasetti, S. Picozzi, and A. Continenza, Phys. Rev. B 64, 235312 (2001).

${ }^{86}$ S. Tanaka, T. Tamura, K. Okazaki, S. Ishibashi, and M. Kohyama, Mater. Trans. 47, 2690 (2006).

${ }^{87}$ M. Kohyama and J. Hoekstra, Phys. Rev. B 61, 2672 (2000).

${ }^{88}$ G. P. Das, P. Blöchl, O. K. Andersen, N. E. Christensen, and O. Gunnarsson, Phys. Rev. Lett. 63, 1168 (1989).

${ }^{89}$ J. P. A. Charlesworth, R. W. Godby, and R. J. Needs, Phys. Rev. Lett. 70, 1685 (1993).

${ }^{90}$ S. Tanaka and M. Kohyama, Phys. Rev. B 64, 235308 (2001).

${ }^{91}$ J. Hoekstra and M. Kohyama, Phys. Rev. B 57, 2334 (1998).

${ }^{92}$ W. Y. Ching, Y.-N. Xu, P. Rulis, and L. Ouyang, Mater. Sci. Eng., A 422, 147 (2006).

${ }^{93}$ J.-Y. Wang and Y.-C. Zhou, Phys. Rev. B 69, 144108 (2004).

${ }^{94}$ Z. Wang, S. Tsukimoto, M. Saito, and Y. Ikuhara, Appl. Phys. Lett. 94, 252103 (2009).

${ }^{95}$ B. J. Johnson and M. A. Capano, Solid-State Electron. 47, 1437 (2003).

${ }^{96}$ L. Kassamakova, R. Kakanakov, I. Kassamakov, N. Nordell, S. Savage, E. Svedberg, and L. Madsen, Mater. Sci. Forum 338342, 1009 (2000).

${ }^{97}$ M. W. Barsoum and T. El-Raghy, J. Am. Ceram. Soc. 79, 1953 (1996).

${ }^{98}$ S. Li, R. Ahuja, M. W. Barsoum, P. Jena, and B. Johansson, Appl. Phys. Lett. 92, 221907 (2008).

${ }^{99}$ W. Lu, W. C. Mitchel, C. A. Thronton, W. E. Collins, G. R. Landis, and S. R. Smith, J. Electrochem. Soc. 150, G177 (2003).

${ }^{100}$ N. Shibata, A. Goto, S.-Y. Choi, T. Mizoguchi, S. D. Findlay, T. Yamamoto, and Y. Ikuhara, Science 322, 570 (2008).

${ }^{101}$ N. Shibata, S. D. Findlay, S. Azuma, T. Mizoguchi, T. Yamamoto, and Y. Ikuhara, Nature Mater. 8, 654 (2009).

${ }^{102}$ J. Wang, T. Liu, and Z. Wang, Mater. Trans. 50, 2115 (2009).

${ }^{103}$ M. Okude, A. Ohtomo, T. Kita, and M. Kawasaki, Appl. Phys. Express 1, 081201 (2008). 